\title{
Maintenance of observing responses with the less highly valued stimulus in pigeons*
}

\author{
STEPHEN B. KENDALL \\ University of Western Ontario, London, Ontario, Canada
}

\begin{abstract}
Previous research has shown that the more valued stimulus will maintain observing responses but the less valued stimulus will not. In the first part of this experiment, it was shown that the removal of the stimulus associated with the fixed-ratio component of a multiple schedule (mult FI 2 min, FR 35) abolished observing responses. In the next part, the ratio stimulus was phased out by making it available during some ratios but not during others. Observing responses were maintained following the phasing procedure even when all ratio stimuli were unavailable. In the third part, all stimuli, both ratio and interval, were unavailable. Observing responses declined under this condition and increased again when the stimulus associated with the interval was again made available. It is hypothesized that observing responses will be maintained as long as they permit the maintenance of a discrimination.
\end{abstract}

An observing response procedure usually involves a successive discrimination or a multiple schedule in which the discrimananda are produced by some behavior of the S (Wyckoff, 1952, 1969). In order that observing responses be maintained, the two components must have differing values for the $S$ (Kendall, 1965) and the stimuli produced by the observing response must be correlated with the components (Wyckoff, 1952, 1969). In Wyck off's experiment with pigeons, the two components were fixed interval and extinction, which insured different values, and the stimuli, which were correlated with the schedules, were colored lights on the response key. The observing response was pressing a pedal which produced the two key colors at appropriate times. Another procedure for producing different values for the components is to punish behavior in one component but not in the other and maintain equal rates of reinforcement in both compartments (Dinsmoor et al, 1969).

If one of the components and its correlated stimulus is removed, leaving the $\mathrm{S}$ continuously in the presence of the other, observing responses will not be maintained (Hendry, 1969b; Kendall, 1972). However, if one of the stimuli is removed while leaving both components in the situation, observing responses may or may not be maintained. In this context, removing a stimulus means making it unavailable so that it will not be produced when an observing response occurs. An observing response during the alternative component will still produce the stimulus associated with that component. In the situation just described, removal of the stimulus associated with the more highly valued component will lead to a severe decrement or the cessation of observing behavior. Removal of the less highly valued stimulus usually results in no observing response decrement

\footnotetext{
*This research was sponsored by a grant from the National Research Council of Canada. The author is indebted to Neil Naft and Anne Newby for their invaluable assistance. Reprints may be obtained from the author, Department of Psychology, University of Western Ontario, London, Ontario, Canada.
}

(Dinsmoor, Flint, Smith, \& Viemeister, 1969; Dinsmoor, Browne, \& Lawrence, 1972; Kendall \& Gibson, 1965; Kendall, 1972). In none of these experiments has there been any independent test of which stimulus is "more highly valued" or "less highly valued"; the stimulus that is associated with the shorter delay to reinforcement, with reinforcement as opposed to nonreinforcement, or with reinforcement without punishment as opposed to reinforcement with punishment is referred to as the "more highly valued."

Suppose that the following statement is true: "Observing responses may be maintained in a situation where the less highly valued stimulus is available, but the more highly valued stimulus is not." If this is so, why have all of the data from the experiments cited above shown otherwise? One reason may run as follows. The more highly valued stimulus reinforces the observing response and is its main source of support. When it is removed, observing responses undergo rapid extinction. Because of this rapid extinction, the animal never has a chance to learn that an observing response which produces no stimulus is associated with the more highly valued component. If the extinction procedure were slowed down or if the animal were provided with some other way of learning this, then observing responses might be maintained.

The experiment reported here is an attempt to test this hypothesis by the use of a procedure that may be called "phasing out" of the more highly valued stimulus. In the phasing out procedure, the stimulus associated with the more highly valued schedule is not presented on some occasions when the animal emits an observing response. On other occasions, however, the more highly valued stimulus is still available and an observing response will produce it. Over the course of several experimental sessions, the more valued stimulus is available on fewer and fewer occasions, until finally it is never presented. This procedure is suggested by the related procedure of "fading" (Terrace, 1966), which is 
usually accomplished by adjusting the intensity or duration of a stimulus.

\section{METHOD}

\section{Subjects}

The Ss were three experimentally sophisticated pigeons, Birds 1 and 3 were male Silver Kings and Bird 2 was a male White King. All birds had served in observing response procedures in which a green keylight had been associated with the delivery of food and a red keylight had been associated with the delivery of time-out.

\section{Apparatus}

The apparatus consisted of a Lehigh Valley Electronics pigeon chamber with two pecking keys. The keys could be transilluminated with white, green, red, or yellow. Each key required about $15 \mathrm{~g}(.15 \mathrm{~N})$ of force to activate the circuitry. The pigeon chamber was housed in a room containing several other chambers. The room was provided with white masking noise. Programming of experimental events and recording of responses were accomplished with electromechanical equipment.

\section{Procedure}

Since in a previous experiment food had been dependent on not pecking in green and red lights, keypecking was trained by successive approximations to the left response key when it was illuminated red, green, or white. The right key remained dark. The reinforcer was $3.5 \mathrm{sec}$ access to mixed grain. During grain presentations the keylight and houselight went out and the feeder light went on. These stimulus conditions prevailed throughout the entire course of the experiment. Forty reinforcers were given per session throughout the experiment.

Following keypeck training, the birds were placed on a multiple schedule of reinforcement with a fixed-ratio and a fixed-interval component. The green light (SFR) transilluminated the response key during the ratio and the red light (SFI) during the interval. Initially the interval was short and the ratio was low. Over the course of 7 to 10 sessions, the interval was increased to $2 \mathrm{~min}$ (FI $2 \mathrm{~min}$ ) and the ratio to 35 responses (FR 35). Half of the components per session were ratios and half were intervals, following each other in an unpredictable sequence. The birds remained in this condition for approximately 20 sessions so their performance could stabilize. The only stability criterion used in this phase was that the cumulative response records display performances such as are typically seen on a multiple schedule of this type (Ferster \& Skinner, 1957). This includes well developed "scalloping" during the interval and a high, steady response during the ratio.

When multiple schedule con trol, as described above, had been achieved, the birds.were given some training in the white light. In this stage (mixed schedule), the white light transilluminated the response key regardless of whether the interval or the ratio was in effect. The birds were given enough training in the white light to insure that pecking was strong, and then observing response training was carried out.

Observing response training was conducted by illuminating the right key with yellow light. A peck to the right key (the observing key) produced either the red (SFI) or green (SFR) light on the left key (the food key) depending on which component, ratio or interval, was in effect on the food key. When the bird pecked the observing key, the white light on the food key went out and was replaced by red or green; the yellow light on the observing response key went out, the key remaining dark until the next food reinforcement. Following an observing response, the food key remained illuminated with red or green light until the food reinforcement. Following a food reinforcement, the food key became white and the observing response key became yellow and remained so until the next observing response. Throughout the experiment one response on the observing key was sufficient to produce red or green on the food key (FR 1 on the observing key).

Following observing response training, the birds were allowed about 15 sessions to stabilize. Previous experience with this procedure (Kendall \& Gibson, 1965) indicated that the birds would be expected to make an observing response following almost all grain reinforcers, i.e., they would almost always collect food reinforcement in the presence of green or red keylights and almost never in the presence of the white light. The birds were performing at this level following the 15 sessions of observing response training.

The experiment progressed through several phases from this point on. The steps are given below.

(1) Removal of the green (SFR) light: This procedure was carried out only with Birds 1 and 2. This is a replication of half of the Kendall and Gibson (1965) experiment. In this phase, a peck on the observing key during a ratio did not alter any exteroceptive stimulus condition. The food key remained white and the observing key remained yellow. A peck on the observing key during an interval darkened the observing key and turned the food key red. This procedure was in effect for 12 sessions.

(2) Reinstatement of the green light for Birds 1 and 2: The procedure was exactly like that used before the removal of SFR. The birds were given 17 sessions.

(3) Phasing out of the SFR: Bird 3 participated in this procedure immediately following its observing response training. The phasing procedure involved removing SFR from only a portion of the ratios. In these ratios, the observing response had no effect on key stimuli as in Procedure 1 above. During the other ratios, the observing response produced SFR as usual. An observing response was effective in producing SFI in all intervals. In the first step of the phasing procedure, SFR was not available in $10 \%$ of the ratios. Since the birds were given 40 grain reinforcers per session, 20 on the interval and 20 on the ratio, this meant that an observing response would be ineffective on 2 of the 20 ratios. Following training under these conditions, progressively more ratios were altered, so that an observing response was ineffective in them. The percentages from the beginning to the end of phasing were $10 \%, 20 \%, 30 \%, 40 \%, 50 \%$, $70 \%, 90 \%$, and $100 \%$. The final condition is the same as the previous condition (1), where all green lights were unavailable. The number of sessions given in each successive condition were $18(10 \%), 15(20 \%), 14(30 \%), 8(40 \%), 9(50 \%), 11(70 \%), 19$ $(90 \%)$, and $30(100 \%)$.

(4) Reinstatement of SFR: The green light was made available in all ratios for all birds. Fourteen sessions were given.

(5) Removal of SFR: The green light was made unavailable for all ratios for all birds. Phasing was not used and all ratios were affected simultaneously. Twenty-five sessions were given.

(6) Removal of SFI: In Phase 5 all green had been removed, so that the removal of red meant that no observing response would produce a stimulus change. The food key remained white and the observing key remained yellow throughout the session. Twenty-one sessions were given.

(7) Reinstatement of SFI: An observing response during an interval produced the red light for the duration of the interval, but green was not reinstated and remained unavailable. Eighteen sessions were given.

\section{RESULTS}

The results of all procedures are shown in Figures 1, 2 , and 3 . The independent variable in all figures is the "observing ratio" used by Kendall and Gibson (1965), which is the number of observing responses during a session divided by the number of schedule components during a session. The latter number was set at 40 throughout the experiment. A ratio of 1.0 was the 
maximum obtainable ratio. An observing response was scored for only the first peck to the observing key during a component. If pecks to the observing key occurred following the onset of a stimulus, no further observing responses were scored, since the observing response is the response that produces the stimulus. In parts of the experiment where a stimulus was unavailable, an observing response was scored if the bird made at least one peck to the observing key, but additional pecks did not count as additional observing responses. All of the data points represent mean observing ratios over the last four sessions of a given condition.

Figure 1 shows the results for Birds 1 and 2 of the first abrupt removal of SFR. When each observing response produced a stimulus, the birds made an observing response in almost all schedule components. When the SFR was unavailable, the birds hardly ever pecked the observing key and, when SFR was available again, the observing response returned to its original level. These results replicate the previous results of Kendall and Gibson (1965).

Figure 2 shows the results of phasing out SFR. During

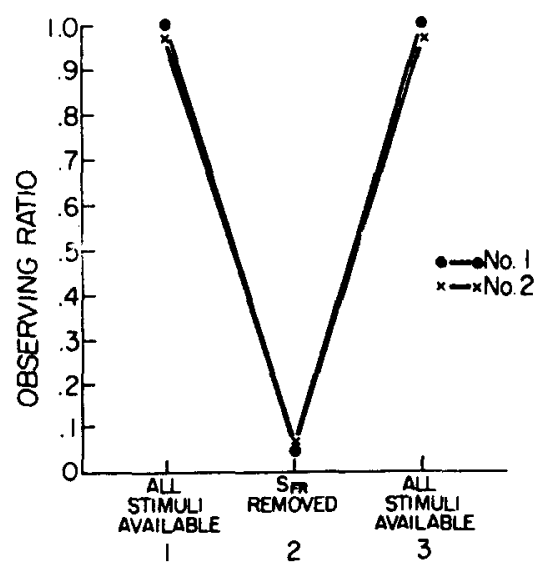

Fig. 1. Observing ratios for Birds 1 and 2 under the original observing response training, with the fixed-ratio stimulus removed and with the fixed-ratio stimulus restored. The numbers 1,2 , and 3 indicate the order of conditions.

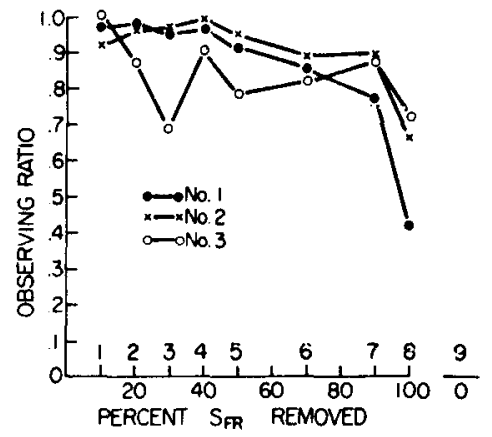

Fig. 2. The effect of phasing out the fixed-ratio stimulus for Birds 1, 2, and 3. The observing response is plotted for each bird for the phasing procedure. The numbers $1-9$ indicate the sequence of conditions as they were run.

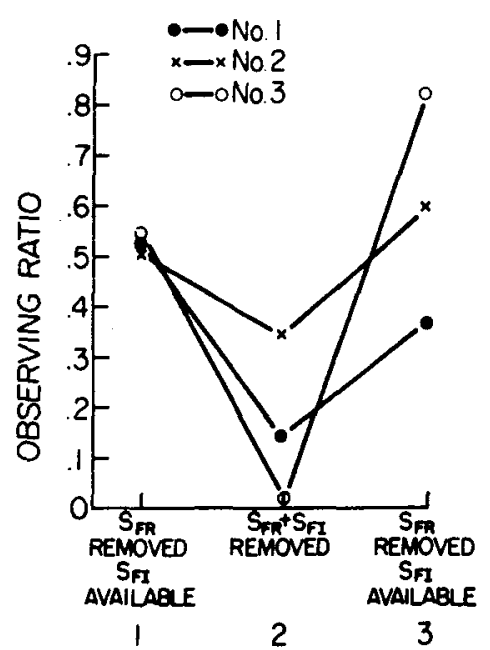

Fig. 3. The effect of changing from the condition where only the fixed-interval stimulus was available to the condition where no stimuli were available and return to the availability of the fixed-interval stimulus. The observing ratio is plotted for Birds 1 , 2 , and 3 . The numbers 1,2 , and 3 indicate the sequence in which the conditions were run.

the course of most of the phasing procedure, the observing ratio was not much affected for Birds 1 and 2 . Bird 3 showed an initial decline in observing responses, reaching a nadir when $30 \%$ of the ratio stimuli were unavailable. This bird recovered better observing response performance with continued training, however. When $90 \%$ of the SFRs were unavailable, the lowest observing ratio was 0.77 (Bird 1). When all of the stimuli were made unavailable, however, the highest observing ratio was 0.71 . Thus, removing the final $10 \%$ of the observing stimuli seemed to affect observing response output. When all green stimuli were reinstated, observing ratios returned to values ranging from 0.96 to 1.00 .

The birds were run for 30 sessions with all of the SFRs unavailable at the end of the phasing portion of the experiments. The observing ratios appeared reasonably stable at the end of this period. This contrasts with the rapid decline that was seen when the green light was abruptly removed for Birds 1 and 2. Both birds were making only one or two observing responses per session at the end of 12 sessions in that portion of the experiment.

Figure 3 shows the results of removing the availability of SFI following the final removal of SFR. The first data point in Fig. 3 was taken following collection of data shown in the last data point in Fig. 2, i.e., during the last four sessions of the condition where SFR was removed. Removal of SFR reduced observing behavior more than removal of SFR at the end of phasing. Observing responses did not cease altogether, however. Removal of SFI meant that no observing response produced a stimulus. There was a decrease in observing responses for all birds. The observing ratio for Bird 2 did not drop greatly, however. Reinstatement of SFI produced an increase in observing responses for all birds. For two 


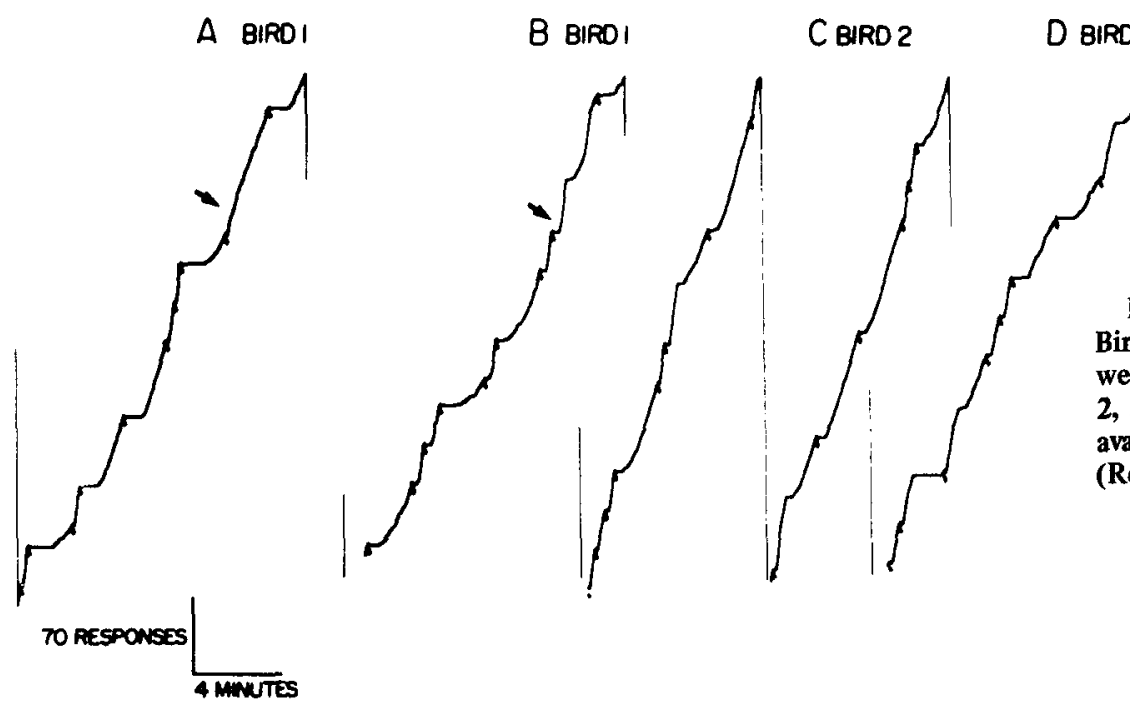

Fig. 4. Sample cumulative records for Bird 1 under the condition where all stimuli were available (Record $A$ ) and for Birds 1 , 2 , and 3 where the fixed-ratio stimulus was available following the phasing procedure (Records B, C, and D).

birds the final observing response output was greater than in the previous phase, where SFI was available (the first data point in Fig. 3).

Figure 4 shows cumulative records of food key performance from two parts of the experiment. The record marked " $A$ " is from Bird 1. It was taken following the phasing procedure, when all SFRs had been made available again (last point in Fig. 3). Since the bird was reliably making observing responses and since all stimuli are available, this record is taken as representative of schedule performance under these conditions. Earlier records with all stimuli available and records from other birds are much the same. The ratios are easily distinguishable from the intervals because of the high rate during the ratios and the pause on the intervals. One interval failed to show a pause (at the arrow). The other three records (B, C, and D) were taken from Birds 1,2, and 3 in the last stage of phasing, when all SFRs were removed. Schedule control is not nearly as good as in most multiple schedules, although intervals and ratios are generally distinguishable. The records shown are not entirely representative, since each was selected to show some instances of fairly good schedule control and some instances of poor schedule control. In Record B, for instance, there is an instance of a high ratio-like rate during an interval (at the arrow). Note that the ratios seem to show a longer pause prior to responding than in Record A taken from the same bird. The interval at the arrow displaying a high rate followed by a small scallop is sometimes seen in mixed schedules with fixed-ratio and fixed-interval components (Ferster \& Skinner, 1957). Records C and D also show various irregularities of schedule control.

\section{DISCUSSION}

The results of the experiment indicated that observing responses may be maintained, at least in some degree of strength, when the more valuable stimulus is not available. This result is in contradiction to previously reported studies which have selectively removed stimuli in an observing response situation (Dinsmoor et al, 1969; Dinsmoor et al, 1972; Kendall \& Gibson, 1965; Kendall, 1972). Some hypotheses concerning this discrepancy will be entertained.

The first hypothesis is that "observing responses" were not maintained at all following the part of the experiment in which the stimulus associated with the ratio was phased out. The results can be attributed to superstitious chaining which developed during the phasing part of the experiment. A peck to the observing key following reinforcement became a part of the entire sequence of reinforced behavior. Thus, the "maintenance" of observing behavior in the absence of the more valued stimulus was produced. This hypothesis is countered by the final manipulation of the experiment, where both SFR and SFI were unavailable. All three birds showed some decrease in observing responses in going from the condition where only SFI was available to the condition where it was not. When SFI was reinstated, all three birds showed an increase in observing behavior. If pecking the observing key during a schedule component was superstitious behavior, this result would not be expected. It is true that one bird did not show a very substantial decrease in observing behavior during this manipulation, but all three birds showed some effect, indicating that the superstition hypothesis is unlikely.

A second hypothesis is that the less valued stimulus, red in the present case, is reinforcing but not as much so as the more valued stimulus, green. This hypothesis has been favored by Hendry (1969a) and Schaub (1969), who have drawn inspiration from the writing of Berlyne (1960). If this argument is true, it is hard to see why no reinforcing value of the less valued stimulus has appeared in previous research, where the more valued stimulus has been abruptly removed. At least one experiment suggests that the less valued stimulus is punishing (Mulvaney, 
Dinsmoor, Jwaideh, \& Hughes, 1974). In their experiment the less valued component was "negative," i.e., one in which reinforcement never occurred. They used two observing response keys. One produced both the more valued (positive) stimulus and the less valued (negative) stimulus. The other key produced only the more valued stimulus during the positive component and had no consequence during the negative component. The birds preferred the observing key that produced only the more valued stimulus. It should be kept in mind that the less valued stimulus in the present experiment was associated with a component in which reinforcement was delivered and, thus, might not be comparable to a less valued component in which no reinforcement was delivered. On the whole, however, other experiments indicate no reinforcing value for the less valued stimulus.

A third hypothesis is that observing responses persist as long as they enable the animal to discriminate between the two reinforcement conditions. It does not matter how the discrimination is made. A peck which does not produce any exteroceptive stimulus change may become a stimulus event which, through the phasing process employed here, becomes correlated with the more valued schedule. The phasing process gives the animal an opportunity to learn this relationship, whereas the abrupt removal of the more valued stimulus removes the only available support for the observing response and no new relationships are learned.

This hypothesis is similar to Wyckoff's original hypothesis that "Exposure to discriminative stimuli will have a reinforcing effect on an observing response to the extent that the subject has learned to respond differently to the discriminative stimuli produced by the observing response [Wyckoff, 1969, p. 237]." Wyckoff was dealing with the case where both discriminative stimuli were available, but it is evident from data on mixed schedules that responses which produce no exteroceptive consequence may nevertheless serve as discriminative stimuli (Ferster \& Skinner, 1957).

A final point in connection with the present experiment concerns the relative strength of observing responses under conditions where the green light was available and where it was not. A comparison between the last two data points in Fig. 2 shows that observing responses occur more frequently where the green light is available (last point) than where the green light is not available (100\% green removed). This difference might be predicted by any theory of observing responses. If the bird finds itself pecking at the white light on the food key, it might be the case that (a) it had made an observing response but there was no stimulus change, hence the current schedule is fixed ratio, or (b) it did not make an observing response, in which case the current schedule is unknown. Thus, the overall value of making an observing response depends on the bird's memory and/or his ability to make discriminations based on its ongoing behavior, i.e., whether or not it is in the middle of a "ratio run." When the green light is available, neither of these factors is crucial.

\section{REFERENCES}

Berlyne, D. E. Conflict, arousal, and curiosity. New York: McGraw-Hill, 1960.

Dinsmoor, J. A., Browne, M. P., \& Lawrence, C. E. A test of the negative discriminative stimulus as a reinforcer of observing. Journal of the Experimental Analysis of Behavior, 1972, 18, 79-85.

Dinsmoor, J. A., Flint, G. A., Smith, R. F., \& Viemeister, N. F. Differential reinforcing effects of stimuli associated with the presence or absence of a schedule of punishment. In D. $R$. Hendry (Ed.), Conditioned reinforcement. Homew ood, Ill: Dorsey, 1969. Pp. 357-384.

Ferster, C. B.. \& Skinner, B. F. Schedules of reinforcement. New York: Appleton-Century-Crofts, 1957.

Hendry, D. P. Introduction. In D. P. Hendry (Ed.), Conditioned reinforcement. Homewood, Ill: Dorsey, 1969a. Pp. 1-33.

Hendry, D. P. Reinforcing value of information: Fixed-ratio schedules. In D. P. Hendry (Ed.), Cond itioned reinforcement. Homew ood, Ill: Dorsey, 1969b. Pp. 300-341.

Kendall, S. B. An observing response analysis of fixed-ratio discrimination. Psychonomic Science, 1965, 3, 28 1-282.

Kendall, S. B. Some effects of response-dependent clock stimuli in a fixed-interval schedule. Journal of the Experimental Analysis of Behavior, 1972, 17, 161-168.

Kendall, S. B., \& Gibson, D. A. The effects of discriminative stimulus removal on observing behavior. Psychological Record, 1965, 15, 545-551.

Mulvaney, D. E., Dinsmoor, J. A., Jwaideh, A. R., \& Hughes, L. G. Punishment of observing by the negative discriminative stimulus. Journal of the Experimental Analysis of Behavior, $1974,21,37-44$.

Schaub, R. E. Response-cue contingency and cue effectiveness. In D. P. Hendry (Ed.), Conditioned reinforcement. Homewood, nll: Dorsey, 1969. Pp. 342-356.

Terrace, H. S. Stimulus control. In W. K. Honig (Ed.), Operant behavior: Areas of research and application. New York: Appleton-Century-Crofts, 1966. Pp. 271-344.

Wyckoff, L. B., Jr. The role of observing responses in discrimination learning. Psychological Review, 1952, 59, 431-442.

Wyckoff, L. B., Jr. The role of observing responses in discrimination learning. In D. P. Hendry (Ed.), Conditioned reinforcement. Homewood, Ill: Dorsey, 1969. Pp. 237-260.

(Received for publication December 3, 1973; revision received April 17, 1974.) 